\title{
Studi Identifikasi Program Campus Social Responsibility Institut Teknologi Sepuluh Nopember (ITS) untuk Meningkatkan Value ITS dan Masyarakat Sekitar
}

\author{
Atika Nur Kiptia, Imam Baihaqi, dan Muhammad Saiful Hakim \\ Jurusan Manajemen Bisnis, Fakultas Teknologi Industri, Institut Teknologi Sepuluh Nopember (ITS) \\ Jl. Arief Rahman Hakim, Surabaya 60111 Indonesia \\ e-mail: ibaihaqi@mb.its.ac.id
}

\begin{abstract}
Abstrak-Salah satu stakeholders dalam lingkungan perusahaan adalah masyarakat. Masyarakat merupakan lingkungan sosial yang terkena dampak dari keberadaan perusahaan, baik dampak positif maupun negatif. Seiring perkembangan globalisasi saat ini maka perusahaan tak hanya dituntut untuk mendapatkan profit, namun juga kontribusi terhadap masyarakat sekitar atau lebih sering dikenal sebagai program Corporate Social Responsibility (CSR). Tak hanya perusahaan yang profit oriented, non profit oriented seperti perguruan tinggi juga mempunyai tanggung jawab terhadap lingkungan sosialnya. Penelitian ini merupakan sebuah penelitian study case pada ITS yang bertujuan untuk melakukan studi identifikasi program CSR ITS. Pendekatan yang digunakan adalah Corporate Shared Value (CSV) dengan value chain sebagai tools untuk analisis aktivitas operasional ITS. Sedangkan metode yang digunakan adalah wawancara secara langsung kepada pihak terkait ITS, aparat kelurahan dan tokoh masyarakat sekitar ITS. Simpulan penelitian ini menunjukkan bahwa kebutuhan masyarakat ITS teringkas dalam 4 aspek yaitu pendidikan, lingkungan, manajemen usaha/bisnis dan pengembangan wilayah pesisir. Terdapat 33 alternatif program CSR ITS yang diusulkan. Selain itu juga terdapat 3 sumber pendanaan untuk pembiayaan alternatif program CSR ITS yang telah disusun.
\end{abstract}

Kata Kunci-Corporate Shared Value, Corporate Social Responsibility, ITS, Value chain..

\section{PENDAHULUAN}

$\mathrm{O}$ RGANISASI yang bisa bertahan adalah organisasi yang bisa menyesuaikan dengan perubahan lingkungan, karena lingkungan merupakan kekuatan yang bisa memengaruhi kinerja organisasi baik secara langsung atau tidak [1]. Pada lingkungan tersebut terdapat stakeholders, yaitu pihak-pihak yang mempunyai kepentingan dan pengaruh terhadap organisasi atau perusahaan [2]. Stakeholders ini terbagi menjadi 2, yaitu internal dan external stakeholders. Seiring perkembangan globalisasi saat ini, perusahaan tak hanya dituntut untuk memperoleh keuntungan untuk kemakmuran internal stakeholder, namun juga diminta untuk memberikan kontribusi positif terhadap lingkungan sosialnya yaitu melalui program Corporate Social Responsibility (CSR).
Pelaksanaan CSR sangat penting bagi perusahaan. Selain melaksanakan kewajiban sesuai kebijakan pemerintah, CSR dapat meningkatkan brand awareness dan brand value perusahaan [3]. Begitu pula menurut [4] yang mengemukakan bahwa CSR memiliki kemampuan untuk meningkatkan citra positif perusahaan. Saat ini, CSR berkembang menjadi konsep "Corporate Shared Value" atau CSV. CSV adalah sebuah konsep dalam strategi bisnis yang menekankan pentingnya memasukkan masalah dan kebutuhan sosial dalam perancangan strategi perusahaan [5]. Perusahaan yang telah menangkap strategi CSV adalah PT Nestle Indonesia dan telah mendapat penghargaan tahunan Sustainable Business Awards (SBA) selama tiga tahun berturut-turut.

Tak hanya perusahaan profit, perusahaan non profit juga mempunyai tanggung jawab terhadap lingkungan sosial dan lingkungan alam yang merupakan sebuah legal entity. Salah satu contoh perusahaan non profit adalah perguruan tinggi. Perguruan tinggi di Indonesia yang keberadaannya sudah lebih dari setengah abad dan memiliki kualitas cukup baik salah satunya adalah ITS. ITS sudah berdiri selama 59 tahun. Selama itu pula ITS beroperasi dengan berpedoman pada Tri Dharma Perguruan Tinggi salah satunya Pengabdian kepada Masyarakat yang bisa diklaim sebagai CSR ITS.

Menurut [6] implementasi CSR ITS belum benar-benar sesuai apa yang dibutuhkan masyarakat sekitar, komunikasi dan sosialisasi kepada masyarakat sangat kurang, masih belum mengarah kepada program CSR yang berkelanjutan dan belum terkoordinasi dengan baik. Pada penelitian ini, peneliti melakukan studi pendahuluan roadmap CSR ITS dengan mempertimbangkan Renstra ITS 2008-2017 dan Renop 20082011. Hal ini penting dilakukan untuk memberi rekomendasi kepada ITS terkait pedoman pelaksanaan kegiatan CSR ITS agar CSR ITS bisa terkoordinasi dengan baik dan terintegrasi. Tujuan penelitian ini adalah menganalisis kondisi dan kebutuhan masyarakat sekitar ITS, mengidentifikasi pengelolaan CSR ITS saat ini dan studi identifikasi program CSR ITS untuk meningkatkan value ITS dan masyarakat sekitar. Adanya penelitian ini diharapkan menjadi problem solving masyarakat sekitar ITS dan menjadi pedoman program CSR ITS yang berkelanjutan. 


\section{LANDASAN TEORI}

\section{A. Corporate Social Responsibility}

CSR didefinisikan sebagai komitmen perusahaan untuk berperilaku etis dan berkontribusi terhadap pengembangan ekonomi [7]. Sedangkan CSR menurut [8] yaitu tanggung jawab atas keberadaan perusahaan kepada lingkungan sosialnya. Induk organisasi standarisasi internasional yaitu ISO (International Organization for Standardization) memberikan guidance untuk mengatur CSR ini yaitu dengan ISO 26000 yang diperuntukkan buka hanya bagi korporasi tetapi bagi semua bentuk organisasi baik swasta maupun publik. Pada ISO 26000, terdapat 7 unsur utama pelaksanaan CSR yaitu pengembangan masyarakat, konsumen, praktek kegiatan institusi yang sehat, lingkungan, ketenagakerjaan, hak asasi manusia, dan organizational governance (governance organisasi). CSR didefinisikan dalam ISO 26000 sebagai tanggung jawab suatu organisasi atas dampak dari keputusan dan aktivitasnya terhadap masyarakat dan lingkungan. Dari berbagai definisi tersebut, dapat disimpulkan sesuai penelitian penulis bahwa definisi CSR yaitu tanggung jawab perusahaan untuk memberikan dampak positif terhadap masyarakat sekitar baik dari segi lingkungan dan pembangunan berkelanjutan. Selain itu, penelitian ini juga merujuk pada definisi CSR yang disampaikan [5] bahwa CSR mampu memberikan value added bagi rantai nilai perusahaan baik dari sudut pandang ekonomi, sosial maupun lingkungan.

\section{B. Corporate Shared Value (CSV)}

Menurut [9] konsep shared value berfokus pada koneksi antara masyarakat dan kemajuan ekonomi yang memiliki kekuatan untuk pertumbuhan global. Konsep shared value mengakui kebutuhan masyarakat bukan hanya kebutuhan ekonomi secara konvensional. CSV merupakan bagian integral dari profitabilitas perusahaan dan posisi kompetitif. CSV memanfaatkan penggunaan sumber daya dan keahlian perusahaan untuk menciptakan nilai ekonomi melalui terciptanya nilai sosial.

\section{Value Chain}

Menurut [10] rantai nilai merupakan media yang digunakan untuk identifikasi aktivitas perusahaan yang mungkin memiliki keuntungan sosial pada setiap rantai nilai aktivitasnya. Pada setiap rantai nilai diharapkan dapat meningkatkan keuntungan dan mengurangi biaya rantai.

\section{METODE PENELITIAN}

Penelitian ini merupakan penelitian studi kasus pada ITS Surabaya. menghasilkan rekomendasi untuk penyusunan sebuah roadmap CSR. Jenis data yang digunakan dalam penelitian ini yaitu data primer dan data sekunder. Berikut merupakan tahap-tahap penelitian:

\section{A. Kondisi Kekinian Masyarakat Sekitar ITS}

Pada tahap ini dilakukan wawancara langsung sebagai data primer kepada aparat kelurahan dan tokoh masyarakat untuk mengetahui kondisi kekinian masyarakat sekitar ITS yaitu masyarakat daerah ring 1 ITS yang meliputi Kelurahan Gebang Putih, Keputih dan Kejawan Putih Tambak. Selain itu juga menggunakan data sekunder dengan menggunakan data Kelurahan dalam Angka BPS, 2014.

\section{B. Pengelolaan CSR ITS}

Tahap ini dilakukan wawancara kepada Ketua Pusat Studi Pusat Studi Potensi Daerah dan Pemberdayaan Masyarakat (PDPM) ITS dan Sekretaris ITS untuk mengetahui pengelolaan CSR ITS. Selain itu juga menggunakan data BPS ITS tahun 2016.

\section{Value Chain Analysis}

Pada tahap ini dilakukan pemetaan proses aktivitas ITS baik aktivitas utama dan aktivitas pendukung. Aktivitas utama terdiri dari aktivitas inbound logistics, operations, outbound logistics, marketing and sales dan service. Sedangkan aktivitas pendukung terdiri dari aktivitas keuangan ITS, sarana dan prasarana ITS, aktivitas perkantoran dan aktivitas terkait human resources management.

\section{Identifikasi Program CSR ITS dengan Shared Value}

Pada tahap ini dilakukan identifikasi kepentingan ITS dan hubungan dengan masyarakat dari setiap aktivitas operasional ITS dalam value chain analysis. Kemudian direkomendasikan alternatif program CSR ITS yang merupakan win-win solution dari kedua pihak yaitu ITS dan masyarakat sekitar. Dijelaskan pula indikator keberhasilan dan model pembiayaan dari program CSR ITS yang telah disusun.

\section{ANALISIS DAN DISKUSI}

\section{A. Analisis Kondisi Kekinian Masyarakat Sekitar ITS}

Kondisi masyarakat sekitar ITS saat ini yaitu mempunyai tingkat kesejahteraan yang menengah ke bawah. Dari kondisi tersebut diperoleh kebutuhan masyarakat sekitar ITS sebagai berikut:

1. Jumlah usaha makanan atau UKM banyak namun manajemennya kurang bagus sehingga perlu pelatihan dan pendampingan UKM.

2. Pelatihan yang bisa meningkatkan taraf hidup masyarakat (output pelatihan: bisa membuka usaha sendiri).

3. Pelatihan dengan sertifikasi sebagai modal kerja.

4. Bantuan pemasaran untuk meningkatkan penjualan UKM.

5. Banyak tenaga kerja yang direkrut dari masyarakat.

6. Bantuan fasilitas untuk nelayan.

7. Budidaya hutan mangrove.

8. Mahasiswa semakin bersosialisasi, aktif berpartispasi kegiatan warga, dan menjaga attitude yang baik.

9. Paling penting pendidikan untuk menggerakkan anakanak SD-SMA khususnya bagi anak kurang mampu.

10. Kemudahan untuk masuk menjadi mahasiswa ITS.

11. Manajemen pengelolaan lingkungan.

12. Lahan untuk pengelolaan sampah.

13. Pelatihan mengelola sampah. 


\section{B. Pengelolaan CSR ITS}

Program CSR yang telah dilaksanakan ITS dari sudut pandang ITS sendiri dan masyarakat dibagi mejadi 3 aspek yaitu bidang ekonomi, sosial dan lingkungan. Hal ini berdasarkan konsep [5] yang bahwa CSR mampu memberikan value added bagi rantai nilai perusahaan baik dari sudut pandang ekonomi, sosial maupun lingkungan. Pada bidang ekonomi terdapat 9 program ITS yang telah diimplementasikan, sedangkan pada bidang sosial terdapat 5 program ITS yang telah diimplementasikan, dan 4 program CSR ITS yang telah diimplementasikan pada bidang lingkungan.

\section{Value Chain Analysis ITS dan Shared Value}

Pada gambar 1. merupakan analisis value chain ITS yang kemudian didapatkan kepentingan ITS dan hubungan dengan masyarakat. Kemudian disusun alternatif program CSR ITS berdasarkan shared value yaitu menyeimbangkan kepentingan ITS dengan kepentingan sosial. Adapun analisis value chain ITS ditunjukkan gambar 1 .

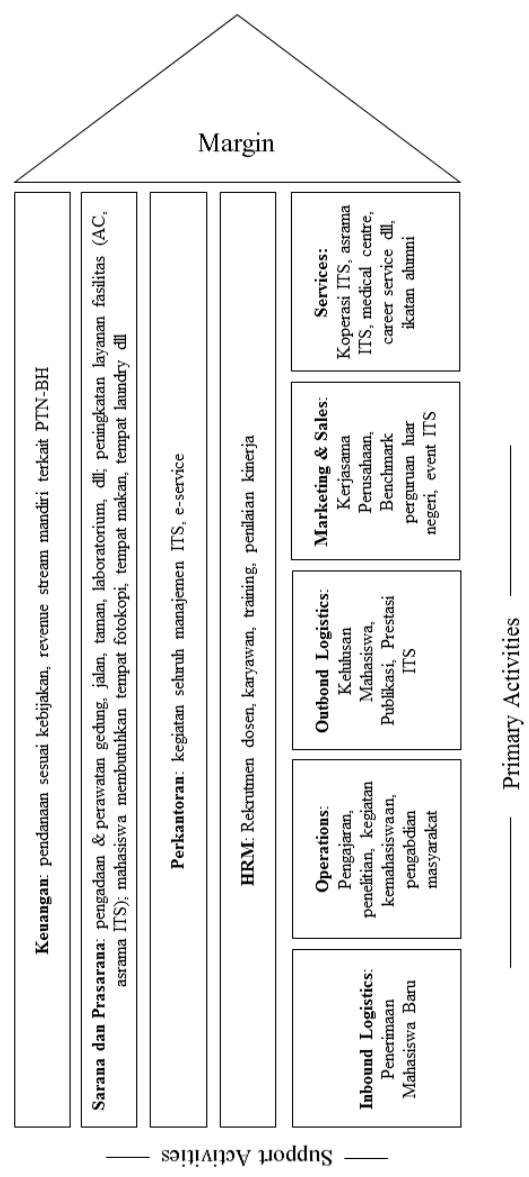

Gambar 1 Analisis Value Chain ITS

Dari analisis value chain tersebut, didapatkan 33 alternatif program CSR ITS yang dikelompokkan menjadi 3 aspek yaitu ekonomi, sosial dan lingkungan sebagai berikut:

a. Bidang Ekonomi

Pada aspek ekonomi atau bisnis masyarakat, alternatif program CSR yang disusun bertujuan untuk mengembangkan usaha masyarakat sehingga bisa menjadi supplier atau mitra
ITS. Mitra tersebut terdiri dari mitra langsung maupun tidak langsung. Mitra tidak langsung merupakan mitra yang tidak berhubungan secara langsung dengan aktivitas operasional ITS berbasis value chain analysis. Sedangkan mitra langsung yaitu mitra yang berhubungan secara langsung dengan aktivitas operasional ITS berbasis value chain analysis. Setelah dijadikan mitra, maka akan diberi pelatihan dan pendampingan usaha oleh pihak ITS. Pada tabel 1 berikut disajikan jenis-jenis mitra ITS beserta pelatihan dan pendampingan.

Tabel 1.

Mitra ITS dari Alternatif Program CSR ITS

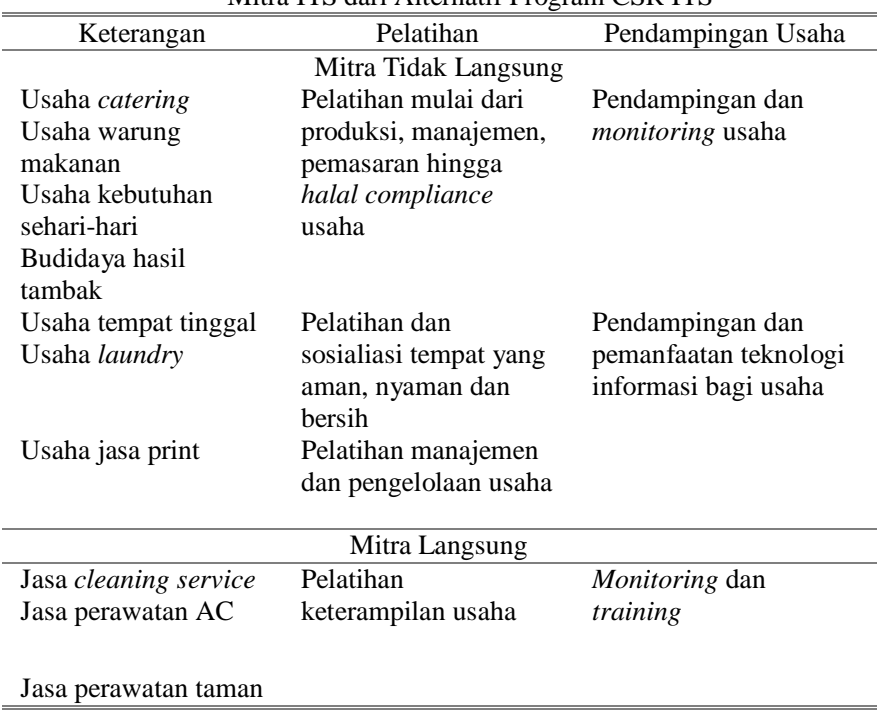

b. Bidang Sosial

Aspek sosial terdiri dari program-program CSR untuk kesejahteraan hidup masyarakat dan hubungan sosial antara stakeholder ITS dengan masyarakat sekitar. Aspek sosial tersebut terdiri dari program-program berikut:

1. Melakukan bimbingan belajar pelajar khususnya pelajar SMA.

2. Melaksanakan pelatihan untuk meningkatkan kompetensi guru sekolah.

3. Mengadakan event hiburan untuk menjaga hubungan baik, seperti sunatan masal, bantuan hewan qurban dll.

c. Bidang Lingkungan

Aspek lingkungan terdiri dari program-program CSR ITS yang bertujuan untuk membangun infrastruktur yang membangun lingkungan sekitar ITS menjadi bersih, aman, nyaman dan menarik. Infrastruktur tersebut terdiri dari beberapa progam CSR ITS seperti:

1. Melakukan sosialisasi kampung tahan banjir rob.

2. Branding pemukiman warga dengan desain artistic dan kampung tematik.

3. Membangun fasilitas sarana pembelajaran.

4. Menyediaan fasilitas sampah.

5. Membangun jamban pada masyarakat yang kurang. mampuMelakukan pembangunan infrastruktur jalan pada kawasan mangrove.

6. Membangun taman terutama di bantaran tepi sungai.

4.1 Model Pembiayaan

Pembiayaan program CSR ITS terbagi menjadi 3 opsi. Opsi pertama yaitu model pembiayaan dari kerjasama dengan 
perusahaan mitra ITS. Perusahaan mitra ITS terdiri dari mitra tidak langsung dan mitra langsung. Kerjasama dengan perusahaan mitra tidak langsung contohnya seperti usaha catering dan kuliner masyarakat yang bekerjasama dengan koperasi ITS. Hal ini menunjukkan bahwa apabila ITS ingin melaksanakan program CSR ITS bisa mengurangi penggunaan anggaran dana yang telah disediakan dengan cara bekerjasama dengan perusahaan mitra. Dengan ini juga telah sesuai dengan konsep shared value [5] program CSR adalah bukan yang program yang disediakan dananya dan untuk disumbangkan atau diberikan bantuan tanpa ada hubungan timbal balik yang berkelanjutan. Adapun program-program CSR ITS yang bisa menggunakan pembiayaan dengan kerjasama perusahaan mitra adalah alternatif program CSR yang telah dikelompokkan pada bidang ekonomi. Hal ini dikarenakan pada bidang tersebut didominasi oleh pelatihan dan pengembangan usaha yang tujuannya adalah agar bisa menjadi mitra dan bekerja sama dengan ITS.

Opsi kedua yaitu model pembiayaan program CSR ITS yang berasal dari program penelitian dan pengabdian masyarakat baik dilakukan oleh dosen maupun mahasiswa. Bagi para dosen ITS, program penelitian dan pengabdian masyarakat ini adalah sebuah kewajiban karena merupakan salah satu aktivitas yang tercantum pada Tri Dharma Perguruan Tinggi. Sementara bagi para mahasiswa, lebih banyak melaksanakan program pengabdian masyarakat dibanding program penelitian. Hal ini dikarenakan pada hampir setiap himpunan jurusan dan BEM mempunyai program pengabdian masyarakat. Contohnya saja seperti himpunan mahasiswa Manajemen Bisnis ITS (BMSA) yang melakukan pengabdian masyarakat melalui program CSR yaitu TAP (Teaching Againts Poverty), sebuah kegiatan bimbingan belajar untuk para pelajar di balai RW 4 Kejawan Gebang atau himpunan Material dan Metalurgi (HMMT) yang mempunyai program CSR berupa kampung binaan. Sedangkan untuk contoh penelitian yaitu seperti program implementasi Sistem Pembangkit Listrik dari Limbah Cair Mesin Cuci Untuk Mereduksi Pencemaran Lingkungan dan Meningkatkan Efisiensi di UKM GD Laundry Keputih Surabaya. Programprogram penelitian dan pengabdian masyarakat seperti itu membuat program CSR bisa terlaksana sesuai kepentingan ITS sendiri namun juga sesuai kepentingan masyarakat (shared value). Kepentingan ITS disini yaitu ITS melaksanakan penelitian yang bisa meningkatkan jumlah publikasi ITS yang nantinya bisa membuat reputasi ITS semakin meningkat. Sedangkan bagi masyarakat bisa meningkatkan taraf kehidupan dengan produktivitas tinggi karena mendapat arahan dan pelatihan serta pendampingan dari ITS untuk mengatasi permasalahan yang ada di masyarakat. Adapun alternatif program CSR ITS yang menggunakan model pembiayaan ini yaitu program CSR bidang ekonomi yang mengarah kepada mitra tidak langsung seperti program CSR ITS untuk pendampingan tempat tinggal yang nyaman, bersih dan aman; program CSR ITS untuk pelatihan catering, pengolahan asap bandeng, perancangan social media marketing. Selain bidang ekonomi, juga untuk program CSR ITS bidang lingkungan seperti program CSR ITS untuk kampung binaan yang dengan palatihan potensi lokal yang dijadikan produk unggulan, perbaikan sarana kebersihan lingkungan, sampah dan pelatihan keterampilan usaha secara berkelanjutan.
Selanjutnya yaitu model pembiayaan opsi ketiga yaitu model pembiayaan kerjasama dengan alumni. Kerjasama alumni ini memprioritaskan bagi program-program CSR ITS untuk pendidikan dan pembangunan lingkungan seperti bimbingan pelajar, pelatihan kompetensi guru dan keterampilan usaha. Alumni dapat memberikan bantuan berupa sumbangan dana yang dapat dialokasikan untuk alternatif program CSR ITS berupa event hiburan sebagai event yang bisa menjaga hubungan baik antara masyarakat sekitar ITS dengan pihak ITS. Program-program CSR ITS yang seperti ini pembiayaannya dapat diperoleh dengan kerjasama alumni ITS yaitu IKA ITS. IKA ITS merupaka ikatan alumni ITS yang mana organisasinya terbagi menjadi 2 yaitu organisasi pada komisariat jurusan dan organisasi pengurus wilayah. IKA ITS mempunyai donasi alumni dan dana abadi.

Dana abadi merupakan sekumpulan dana yang dihimpun dan disimpan secara permanen pada suatu dana investasi, yang hasil investasinya dapat digunakan untuk mencapai visi dan misi ITS. Tujuan awalnya adalah untuk menjaga keberlangsungan dan masa depan universitas, agar mampu mandiri dengan tetap mempertahankan kualitasnya. CSR ITS merupakan salah satu cara untuk mencapai salah satu misi ITS yaitu misi pada bidang pengabdian masyarakat, maka program CSR ini bisa mendapatkan modal pembiayaan dari dana abadi dari para alumni. Dana abadi tersebut bisa digunakan untuk programprogram CSR ITS yang telah diusulkan seperti bimbingan pelajar atau pemberian beasiswa

\section{SIMPULAN}

Berdasarkan tujuan penelitian, didapatkan simpulan penelitian sebagai berikut:

1. Kondisi masyarakat sekitar ITS saat ini yaitu mempunyai tingkat kesejahteraan yang menengah ke bawah sehingga memerlukan pelatihan dan pembinaan untuk meningkatkan kesejahteraan tersebut baik dari segi pengembangan ekonomi masyarakat, peningkatan infrastuktur untuk menciptakan lingkungan yang aman, nyaman dan bersih serta peningkatan sosial masyarakat.

2. Pengelolaan CSR ITS saat ini masih belum terstruktur dan terdapat kesenjangan antara program CSR ITS yang telah dilaksanakan dengan kondisi dan kebutuhan masyarakat

3. Terdapat 33 alternatif program CSR yang menjadi rekomendasi berdasarkan gap analysis dan service value chain ITS. Alternatif program CSR ITS tersebut dikelompokkan menjadi 3 aspek. Pertama yaitu aspek ekonomi atau pengembangan usaha yang mana ITS menjalin mitra dengan masyarakat sekitar sehingga diperoleh program CSR ITS yang berkelanjutan. Kedua yaitu aspek sosial atau ceremonial. Ketiga yaitu aspek lingkungan atau pembangunan. Program CSR ITS tersebut selanjutnya mempunyai model pembiayaan yaitu model pembiayaan dengan kerjasama perusahaan mitra ITS, pembiayaan dengan program penelitian dan pengabdian masyarakat dan pembiayaan dari kerjasama alumni.

\section{SARAN}

Saran yang dapat diberikan berdasarkan hasil penelitian yang telah dilakukan adalah ITS sebagai perguruan tinggi apalagi 
sudah berakreditasi PTN-BH harus semakin meningkatkan perhatiannya dengan CSR khususnya CSR untuk masyarakat sekitar ITS. CSR yang dilaksanakan ITS lebih baik CSR yang tidak hanya sekedar memberi namun juga "take and give". ITS memberi CSR yang bisa membuat masyarakat berkembang dan masyarakat juga bisa berkontribusi kepada ITS (win win solution).

Sedangkan saran bagi dunia penelitian sendiri yaitu penelitian CSR pada perguruan tinggi masih sangat sedikit dilakukan sehingga diharapkan penelitian seperti ini lebih banyak dilakukan khususnya bagi perguruan tinggi yang berPTN-BH atau instansi pendidikan swasta yang harus mempunyai image yang bagus pada masyarakat. Selain itu, studi pendahuluan penyusunan roadmap CSR ITS lebih baik dilanjutkan pada penelitian selanjutnya dengan roadmap yang lebih detail yaitu terdiri dari program CSR ITS, indikator keberhasilan, anggaran biaya, tahun pelaksana per tahun dan per bulan, penanggung jawab pelaksana, dan tempat pelaksana. Tools yang digunakan juga bisa diubah sesuai dengan kebaruan penelitian selanjutnya atau tools lain yang lebih mengarah ke CSR, seperti tools ISO 26000.

\section{DAFTAR PUSTAKA}

[1] Hensi, M. (2012). Lingkungan Manajemen, Budaya Perusahaan, Etika Manajerial, dan Tanggung Jawab Sosial Perusahaan.

[2] Hunger, J. D., \& Wheelen, T. L. (2011). Strategic Managemen and Business Policy: Toward Business Globalization 13th Edition. Pearson.

[3] Kotler, P., \& Lee, N. (2005). Corporate Social Responsibility, Doing the Most Good for Your Company and Your Cause. Canada: John Wiley \& Sons, Inc

[4] Porter, M., \& Kramer, M. (2006). Strategy and Society: The Link Between Competitive Advantage and Corporate Social Responsibility. Harvard Business Review 1 December.

[5] Moir, L. (2001). What do we mean by corporate social responsibility? Corporate Governance: The international journal of business in society, Vol. 1 Iss 2 pp. 16 - 22.

[6] Lawrence, A. T. (2008). Business and Society Stakeholders, Ethics, Public Policy. New York: McGraw-Hill/Irwin.

[7] Porter, M., \& Kramer, M. (2011). Creating Shared Value. Harvard Business Review.

[8] Tsai, W., \& Hsu, J. (2008). Corporate Social Responsibility Programs Choice and Costs Assesment

[9] Porter, M. (1985). Competitive Advantage, The Free Press. New York. 